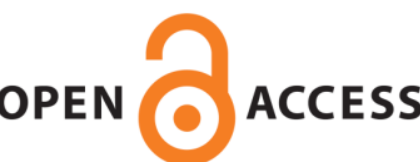

UWS Academic Portal

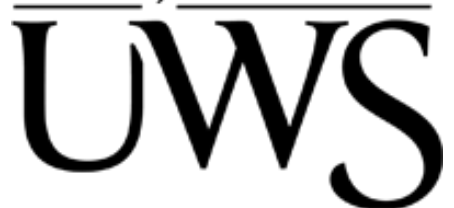

\title{
Feasibility of individualized aerobic threshold based exercise on ventilatory efficiency in sedentary adult asthma patients
}

Peric, Ratko; Drobnic, Franchek M.; Baker, Julien S.

Published in:

Minerva Pneumologica

DOI:

$10.23736 / S 0026-4954.18 .01829-1$

Published: 31/12/2018

Document Version

Peer reviewed version

Link to publication on the UWS Academic Portal

Citation for published version (APA):

Peric, R., Drobnic, F. M., \& Baker, J. S. (2018). Feasibility of individualized aerobic threshold based exercise on ventilatory efficiency in sedentary adult asthma patients. Minerva Pneumologica, 57(4), 92-98.

https://doi.org/10.23736/S0026-4954.18.01829-1

\section{General rights}

Copyright and moral rights for the publications made accessible in the UWS Academic Portal are retained by the authors and/or other copyright owners and it is a condition of accessing publications that users recognise and abide by the legal requirements associated with these rights.

Take down policy

If you believe that this document breaches copyright please contact pure@uws.ac.uk providing details, and we will remove access to the work immediately and investigate your claim. 


\title{
Original Research
}

\section{Feasibility of individualized aerobic threshold based exercise on ventilatory efficiency in sedentary adult asthma patients}

\author{
Peric Ratko ${ }^{1 *}$, Drobnic M Franchek ${ }^{2}$, Baker S Julien ${ }^{3}$ \\ 1* Institute for Sport and Occupational Medicine, Banja Luka, Bosnia and \\ Herzegovina. \\ ${ }^{2}$ Centre d'Alt Rendiment, Sant Cugat del Valles, Barcelona, Spain. \\ ${ }^{3}$ Institute for Clinical Exercise and Health Sciences, School of Science and Sport, \\ University of the West of Scotland, Hamilton, Lanarkshire, Scotland.
}

*Corresponding author full contact details: Peric Ratko, Zdrave Kodre 4, 78000 Banja Luka, Bosnia.ratkoperic@yahoo.com, 0038765668365. 


\begin{abstract}
Background: The aim of this trial was to assess the feasibility of the future definitive study that will define the effects of aerobic threshold based exercise on ventilatory efficiency in sedentary adult female asthma patients.

Methods: Six female asthma patients performed an individualized aerobic training program for 7 weeks with their ventilatory parameters measured before and after exercise intervention using breath-by-breath gas analysis and graded treadmill test until volitional exhaustion. Paired samples $t$-test was used to compare baseline and control values.

Results: Statistically significant changes in resting ventilatory equivalents for oxygen and carbon-dioxide, increases in exercise capacity, decrease of nadir ventilatory equivalents for oxygen and carbon-dioxide values and a shift of the aerobic threshold and associated heart rate toward higher exercise intensity were noted as a result of training adaptation $(p<0.05)$. The participants' medicament diary demonstrated a decrease in daily inhaled therapy and in personal rating of perceived exertion $(p<$ $0.05)$.
\end{abstract}

Conclusions: These results suggest feasibility of individual aerobic threshold based exercise contribution toward asthma control in asthma patients.

Keywords: Physiology; Therapy; Rehabilitation. 


\section{Introduction}

Asthma represents a chronic disorder of the airways characterized by reversible and intermittent airway obstruction, airway inflammation and hyperactivity of the airways. ${ }^{1}$ This disorder is placing a substantial strain on the health care system due to high prevalence and overall burden. ${ }^{1}$ Individuals with moderate and severe asthma have difficulty performing normal daily tasks, which limits their physical activity and results in exercise avoidance, directly affecting everyday life quality. ${ }^{2}$ Studies have shown that asthma associated inactivity is related with the number of hospitalizations and is known as the strongest predictor of all-cause mortality due to peripheral muscle wasting and deconditioning of the respiratory and skeletal muscles. ${ }^{2,3}$ Although asthma patients do not have limited exercise capacity except under acute periods, studies have demonstrated benefits of aerobic exercise, as a part of a pulmonary rehabilitation program, improving asthma control and reducing ailment related factors. ${ }^{4,5,6}$

For this purpose, cardiopulmonary exercise testing (CPET) has demonstrated clinical usefulness in the evaluation of asthma severity and objective determination of exercise intensity. ${ }^{7}$ Furthermore, CPET warrants evaluation of the impact of therapeutic interventions on patients exercise capacity and components of the exercise response directed at improving breathing strategy. ${ }^{7,8}$ Although maximal oxygen uptake $\left(\mathrm{VO}_{2 \max }\right)$ is the most frequently analyzed parameter, additional ventilatory parameters obtained during CPET have demonstrated prognostic value. ${ }^{7,8}$ One of these parameters are ventilatory equivalents for oxygen $\left(\mathrm{VE} / \mathrm{VO}_{2}\right)$ and carbon dioxide $\left(\mathrm{VE} / \mathrm{VCO}_{2}\right.$ ). The $\mathrm{VE} / \mathrm{VO}_{2}$ describes the ratio of ventilation (VE) divided by how much oxygen $\left(\mathrm{O}_{2}\right)$ is consumed with $\mathrm{VE} / \mathrm{VCO}_{2}$ representing the ratio of ventilation divided by how much carbon dioxide $\left(\mathrm{CO}_{2}\right)$ is produced; an index of the ventilatory 
efficiency of the lungs. ${ }^{9}$ The normal $\mathrm{VE} / \mathrm{VO}_{2}$ pattern is a drop early in exercise to its nadir, reaching a point of optimal ventilatory efficiency (PoW) and then an increase as maximal exercise capacity is approached. ${ }^{10,11,12} \mathrm{VE} / \mathrm{VCO}_{2}$ also decreases hyperbolically to minimal values similar to or slightly higher to that of $\mathrm{VE} / \mathrm{VO}_{2} .{ }^{12}$ Analysis of these parameters has proven useful for assessing the presence and severity of lung diseases while allowing an overview of patterns related to the ventilatory response and metabolic demands of exercise. ${ }^{7,8}$ Since inefficiency of ventilation results from presence of high airway resistance and decrease in pulmonary perfusion of the ventilated lung, respiratory abnormalities relative to metabolic demand would be expected in asthma patients. Such abnormalities include a trending of increased resting and nadir $\mathrm{VE} / \mathrm{VO}_{2}$ \& $\mathrm{VE} / \mathrm{VO}_{2}$ values; decreased ventilatory efficiency. ${ }^{7,8}$

Though studies suggest evaluation of exercise capacity as a guide to prescribe exercise intensity by means of percentage of maximal oxygen uptake ( $\% \mathrm{VO}_{2 \max }$ ), recent studies highlighted the fact that using fixed percentages can ultimately lead toward existence of a wide "aerobic exercise zone“, being not individual specific. ${ }^{13,14}$ As a follow-up, some studies reported higher effectiveness of aerobic exercise in different clinical populations when performed as an individualized program of aerobic threshold (AeT) based exercise. ${ }^{13,15,16}$ Obtained during a graded exercise test (GXT) via gas or blood analysis by means of CPET, AeT matches PoW and represents an specific indicator of exercise intensity which in turn could be used for more individual exercise prescription. ${ }^{17}$ Therefore, the prescription of AeT based exercise may be a valid tool to move from a commonly used wide "aerobic exercise zone" to a more optimal individual exercise intensity in asthma patients.

Several studies have examined the effects of AeT based exercise on exercise capacity in asthmatic children. ${ }^{5,18}$ However, currently published data allow no insight 
in the effects of AeT based exercise on ventilatory efficiency and exercise capacity in sedentary adult female asthma patients. If this simple, non-invasive method could be shown to be useful, it might serve to supplement other procedures currently used to monitor clinical course and treatment of asthma providing a more accurate individualised approach.

Based on the above consideration, this trial aimed to examine the feasibility for a future controlled study that aims to assess the benefits of AeT based exercise on ventilatory efficiency and exercise capacity in sedentary adult female asthma patients. In this pilot, we hypothesised how performing exercise at the AeT can provide clinical benefit toward an increase in ventilatory efficiency and exercise capacity, directly affecting everyday life quality in observed population.

\section{Methods}

\section{Study population}

Six sedentary female adults with mild-moderate persistent asthma as defined, ${ }^{1}$ with at least a ten years disease history were eligible for enrolment, with number of the subjects reflecting the availability of patients to participate. Their morphological and anthropometric values were: age $42.8 \pm 4.6$ y, height $165.6 \pm 6.4 \mathrm{~cm}$; weight 66.3 $\pm 4.6 \mathrm{~kg}, \mathrm{BMI}=24.2 \pm 0.11 \mathrm{~kg} \cdot \mathrm{m}^{-2}$. All participants were recruited via personal meetings or personally contacting the testing facility. Prior to testing, all participants completed a questionnaire regarding their health status and activity levels. Furthermore, a physician diagnosis of asthma and documentation evidence was provided. All participants were clinically stable (no changes in standard daily therapy and no quick-relief rescue asthma medicines over the last 3 months prior to study) and using long-acting beta 2-agonists salmeterol in conjunction with corticosteroids via 
metered-dose inhaler therapy two inhales a day $(25 \mu \mathrm{g}$ salmeterol with $250 \mu \mathrm{g}$ fluticasone propionate), $12 \mathrm{~h}$ apart. Furthermore, all participants were closely monitored by their physicians for the duration of the intervention and allowed to use medication therapy as needed. Participants were excluded if they were smokers or demonstrated any other pulmonary disease or if they practiced any organized physical activity prior to this intervention. Participants' characteristics were assessed at the first laboratory visit using a standard stadiometer and a BC - 418 Segmental Body Composition Analyser (TANITA ${ }_{\circledast}$ Tokyo, Japan). Participants were asked to abstain from any physical activity $48 \mathrm{~h}$ prior to the testing sessions and to refrain from consuming caffeine, alcohol, supplementations and additional medications on the testing days. The testing was performed in a laboratory with standardized environmental conditions $\left(21^{\circ} \mathrm{C}, 43 \%\right.$ humidity and $270 \mathrm{~m}$ above sea level). All participants were made familiar with ethical principal of the study, potential health risks and feasibility objectives and willingly singed an informed consent statement regarding publication of the data. The entire research project complied with the policy statement with respect to the Declaration of Helsinki and was approved by the Institutional ethical committee (dr sc Popovic Mira, 255/17, 25.05.2017).

\section{Study intervention}

The participants were enrolled in 7-week exercise program consisting of 60 min aerobic exercise three times a week performed at a heart rate (HR) corresponding to intensity of AeT. All training session were performed in the evening, from 18:00 till 19:00 o'clock. The aerobic exercise program was supervised by a physical therapist and monitored using HR Polar team system (POLAR ${ }_{\circledast}$, Kempele, Finland). In order to produce adequate stimuli, participants were training at intensity matching 
$100 \%-110 \%$ their individual AeT. ${ }^{19}$ Participants were allowed to use medication therapy as needed during the exercise program. Furthermore, they were instructed to continue their everyday nutritional habits, to maintain a diary of medication use and personal rating of perceived exertion log (RPE). The study intervention started with baseline CPET evaluation followed by a 7-week exercise intervention. At the conclusion of the intervention, control CPET assessment was repeated and compared with preliminary data. Measured variables were: $\mathrm{VO}_{2 \max }$, resting $\mathrm{VE} / \mathrm{VO}_{2}$, nadir $\mathrm{VE} / \mathrm{VO}_{2}$, resting $\mathrm{VE} / \mathrm{VCO}_{2}$, nadir $\mathrm{VE} / \mathrm{VCO}_{2}, \mathrm{AeT}$ and matching $\mathrm{HR}$.

\section{Testing protocol}

CPET was performed between 10:00 and 14:00 h for both baseline and control test sessions to avoid circadian variance. In order to obtain required parameters, participants performed GXT on a T170D motorized treadmill (COSMED ${ }_{\circledast}$, Rome, Italy) until volitional exhaustion. Oxygen consumption $\left(\mathrm{VO}_{2}\right)$ and carbon dioxide production $\left(\mathrm{VCO}_{2}\right)$ were assessed during exercise by breath-by-breath Quark PFT Ergo (COSMED ${ }_{\circledast}$, Rome, Italy) system. The system was calibrated before each test by using certificated gas mixtures of known concentrations $\left(\mathrm{O}_{2} 20.93 \%\right.$; $\mathrm{CO}_{2} 5.20$ \%). A 3-L syringe verified the flow of gases. Fluctuations of breath-by-breath data were minimized using a 6 breaths smoothing and consequent 30 sec averaging as instructed by the manufacturer. $\mathrm{VO}_{2 \max }$ obtained was presented in millilitres per kilogram of body weight per minute $\left(\mathrm{ml} \cdot \mathrm{kg}^{-1} \cdot \mathrm{min}^{-1}\right)$ and determined using the following criteria: a respiratory exchange ratio (RER) $\geq 1.15$ or a plateau of $\mathrm{VO}_{2}$ in spite of a load increase. ${ }^{20}$ AeT was determined manually via ventilatory gases and based on the $\mathrm{VE} / \mathrm{VO}_{2}$ method. ${ }^{10}$ Participants $\mathrm{HR}$ was continually monitored with integrated monitoring system (POLAR ${ }_{\circledast}$, Kempele, Finland) and presented in beats 
per minute (beats $\cdot \mathrm{min}^{-1}$ ). The GXT protocol used consisted of three stages: rest, exercise and recovery. The resting stage ( $3 \mathrm{~min}$ ) was performed to obtain baseline values and assure low starting HR. The exercise stage initial speed was $4 \mathrm{~km} \cdot \mathrm{h}^{-1}$ followed by an increase in speed of $1 \mathrm{~km} \cdot \mathrm{h}^{-1}$ every 2 min until volitional exhaustion. Treadmill incline was kept constant at $1 \%$. The subjects were instructed to self-select when the transition from a walking pace to a run occurred. Exercise stage was followed by a 3 min active recovery that consisted of walking at the starting speed in order to observe physiological recovery of the subjects. All participants underwent a 15 min walking trial $24 \mathrm{~h}$ prior to testing to familiarize them with the treadmill and breathing apparatus.

\section{Statistical analysis}

All data were analysed and presented as mean and standard deviation (SD), followed a 95\% confidence interval (CI) using the MedCalc (MEDCALC ${ }_{\circledast}$, Ostend, Belgium) software. Paired samples t-test repeated measures design for pre- and postintervention was used to compare baseline and control values. The Shapiro-Wilk test was used to examine if the measured experimental variables were normally distributed. For all statistical analyses, significance was accepted at $p \leq 0.05$.

\section{Results}

No participants were excluded from the study. According to their body composition and BMI results, all participants fell into the healthy range (BMI $<25$ $\left.\mathrm{kg} \cdot \mathrm{m}^{-2}\right)$. Participants' ventilatory values for pre- and post-intervention with statistical validity can be seen in Table 1 . The paired t-test comparison of pre- and postintervention mean pulmonary scores showed statistically significant changes such as 
decrease of resting $\mathrm{VE} / \mathrm{VO}_{2} \& \mathrm{VE} / \mathrm{VCO}_{2}$ values, increase in general aerobic capacity, decrease of nadir $\mathrm{VE} / \mathrm{VO}_{2}$ \& $\mathrm{VE} / \mathrm{VCO}_{2}$ and shift of AeT associated HR toward higher exercise intensity as a result of training adaptation (Table 2). Improvements in maximal and submaximal exercise tolerance were observed in all subjects (Figure 1). Statistically significant improvements were observed in ventilatory equivalents for $\mathrm{VE} / \mathrm{VO}_{2} \& \mathrm{VE} / \mathrm{VCO}_{2}$, both resting and nadir values (Figure 2).

The participants' medications diary demonstrated decrease in their daily inhaled standard therapy from two times a day, to one time a day while dosage remained the same with no report regarding quick-relief medications usage $(p<0.05)$. Decrease in RPE for exercise sessions and everyday activities were also reported.

No connection was observed when pre- intervention values of $\mathrm{VO}_{2 \max }$ were correlated with pre- intervention AeT ( $r=0.53, p=0.28)$, nadir VE/ $/ \mathrm{VCO}_{2}(r=0.56, p$ $=0.25)$ and nadir $\mathrm{VE} / \mathrm{VO}_{2}(r=0.59, p=0.22)$. However, a post- intervention correlation assessment revealed a positive correlation between $\mathrm{VO}_{2}$ max and nadir $\mathrm{VE} / \mathrm{VO}_{2}(r=0.86, p<0.03)$.

\section{Discussion}

Our pilot intervention results show how 7-weeks of AeT individualized based exercise may be a feasible methodology for improvement of ventilatory efficiency and increase in exercise capacity in adult sedentary female patients with stable asthma. In our study, subjects increased their maximal and submaximal exercise tolerance time by means of both $\mathrm{VO}_{2 \max }$ and $\mathrm{AeT}$ improvement as a result of adaptation to individualized aerobic exercise program. Furthermore, improvements in ventilatory efficiency, both resting and exercise, were observed followed by decrease 
of daily medications usage and decrease of RPE. Although subjects failed to reach healthy subjects values, the magnitudes of the changes are very promising.

Our observations were confirmed by previous studies on asthmatic individuals where improvements in general exercise capacity through marked enhancements in AeT, associated $\mathrm{HR}$ and $\mathrm{VO}_{2 \max }$ values following individualized AeT based training were observed. ${ }^{15,18,21}$ This phenomenon was explained as a general adaptation to aerobic training through improvements in cardiac function and oxygen extraction capacity, being associated with a reduction in exercise-induced bronchospasm, directly increasing the ability of the asthma patients to perform submaximal exercise. $^{22}$ AeT based exercise has been previously recommended as an additional therapy for improvements of ventilatory efficiency in cardiac patients, suggesting possible existence of a safe exercise zone, which could also be used in asthma patients, to maximize the effects of exercise regimes. ${ }^{16,23}$ These studies demonstrated substantial $\mathrm{VE} / \mathrm{VO}_{2}$ slope improvement (6\% to 23\%) after AeT based training programs and match our observation on asthma patients. It is possible that in patients with pulmonary diseases there is a threshold ventilatory rate at which exercise induced bronchoconstriction is triggered enabling better respiratory comfort and argues in favour of the better efficiency of exercise therapy. ${ }^{24}$ To elaborate, if exercise training allows a patient to exercise more before reaching the threshold for triggering exercise induced bronchoconstriction; which we believe to be at intensity somewhat above AeT, that patient may report an increase in exercise capacity and ventilatory efficiency without experiencing exercise induced bronchoconstriction providing a plausible mechanism for our observation. ${ }^{24}$

Poor ventilatory efficiency; increased resting and nadir $\mathrm{VE} / \mathrm{VO}_{2}$ and $\mathrm{VE} / \mathrm{VCO}_{2}$, typical for asthma patients, was observed in our study. Our observation 
was confirmed in previous studies. ${ }^{25,26}$ Ingle et al. (2012) suggested that the high nadir $\mathrm{VE} / \mathrm{VO}_{2}$ and $\mathrm{VE} / \mathrm{VCO}_{2}$ values were the most stable marker of ventilatory inefficiency in asthma patients. Several mechanisms such as ventilation perfusion discrepancy, impaired diffusion of metabolic gases, respiratory muscle weakness and increased sensitivity of peripheral receptors have been suggested as possible causes. ${ }^{1,4}$ Neder et al. (2017) advocates how a high nadir $\mathrm{VE} / \mathrm{VCO}_{2}$ is reciprocally associated with greater exertion dyspnea scores and inferior exercise tolerance in asthma patients. Therefore, beneficial characteristics of AeT based programs may possibly reduce breathlessness and asthma symptoms, but not airway inflammation, by strengthening respiratory muscles, thus decreasing minute ventilation during exercise directly influencing ventilatory efficiency. ${ }^{21}$ However, effects of AeT based exercise on ventilatory efficiency in sedentary asthma patients remain unclear and require further examination.

Furthermore, studies suggest that the both AeT and nadir $\mathrm{VE} / \mathrm{VO}_{2}$ are correlated with $\mathrm{VO}_{2 \max }$ in patients with pulmonary disorders. ${ }^{23,25}$ Our findings however, confirm such connection only in case of nadir $\mathrm{VE} / \mathrm{VO}_{2}$ and $\mathrm{VO}_{2 \max }$, requiring further examination.

Apart from exercise capacity and ventilatory efficiency improvements, subjects reported a decrease in daily medications usage as well as an improvement in daily activity RPE while staying clinically stable (they demonstrated no need for quick relief rescue medications for the duration of the study). Based on CPET evaluation, these improvements were quantified by the participant's physicians. Our observation was previously confirmed. ${ }^{24,27}$ We consider possible improvement in auto knowledge of physical fatigue perception through increase in exercise capacity which leads to improvement in living disciplines as well as better ventilation/perfusion and 
less $\mathrm{CO}_{2}$ retention without bronchoconstriction dyspnoea could offer possible explanation for our observation. However, examining connection between AeT based exercise and medications usage in sedentary adults with asthma requires additional investigation.

Completion of the current intervention highlighted several areas that need to be modified in preparation for a future clinical study. This trial consisted of a single group design based on the availability of subjects and lacked a control group. Future studies should consider the inclusion of a control group to confirm the findings reported here. A control group using asthma patients performing non-individualized aerobic exercise would provide useful comparisons to the data obtained in this trial. These comparisons would substantiate if observed changes were direct result of prescribed AeT individual exercise or coincidence. Our sample size possibly limits our statistical power, however noteworthy differences were observed in variables examined. An adequate sample size will be needed to fully understand the impact of this individual approach. Clinical outcome measures should be expanded to include additional lung function parameters, such as fraction of oxygen and carbon dioxide in expired air $\left(\mathrm{FeO}_{2}, \mathrm{FeCO}_{2}\right)$, dead space over tidal volume ratio (VD/VT), partial pressure of oxygen and of carbon dioxide $\left(\mathrm{PO}_{2}, \mathrm{PCO}_{2}\right)$ etc.

\section{Conclusions}

These results suggest feasibility of usage of AeT based exercise as more individualized exercise approach for asthma patients. Moreover, this novel understanding may provide innovative therapeutic methods, centered on usage of AeT based exercise as a complementing training therapy in the treatment of asthma. 


\section{Authors' contributions}

RP contributed to the study design, data collection and analysis, and manuscript drafting. FD contributed to study design and manuscript drafting. PB contributed to manuscript drafting. JB contributed to study design and manuscript drafting.

\section{Funding sources}

This study received no financial support.

\section{Conflicts of interest}

Authors declare no conflict of interest.

\section{Acknowledgements}

There has been no financial or any other assistance with this project. 


\section{References}

1. Braman SS. The global burden of asthma. Chest 2006; 130 (1):4-12.

2. Oga T, Nishimura K, Tsukino M, Sato S, Hajiro T. Analysis of the factors related to mortality in chronic obstructive pulmonary disease: role of exercise capacity and health status. Am J Respir Crit Care Med 2003; 167: 544-9.

3. Rausch-Osthoff A-K, Kohler M, Sievi NA, Clarenbach CF, van Gestel AJ. Association between peripheral muscle strength, exercise performance, and physical activity in daily life in patients with Chronic Obstructive Pulmonary Disease. Multidisciplinary Respiratory Medicine 2014;9(1):37. doi:10.1186/2049-6958-9-37.

4. Evaristo KB, Saccomani MG, Martins MA, Cukier A, Stelmach R, Rodrigues MR, Santaella DF, Carvalho CR. Comparison between breathing and aerobic exercise on clinical control in patients with moderate-to-severe asthma: protocol of a randomized trial. BMC Pulm Med 2014; 14: 160. doi: 10.1186/1471-246614-160.

5. Wanrooij VH, Willeboordse M, Dompeling E, van de Kant KD. Exercise training in children with asthma: a systematic review. Br J Sports Med 2014; 48 (13):1024-31.

6. Boyd A, Yang CT, Estell K, Tugle MSC, Gerald LB, Dransfield M, Bamman M, Bonner J, Prescott TA, Schwiebert LM. Feasibility of exercising adults with asthma: a randomized pilot study. Allergy Asthma Clin Immunol 2012; 8 (1):13. doi.org/10.1186/1710-1492-8-13.

7. "ATS/ACCP Statement on Cardiopulmonary Exercise Testing". Am J Respir Crit Care Med 2003; 167 (2):211-77. 
8. American College of Sports Medicine. Guidelines for exercise testing and prescription. Lipincott Williams and Wilkins: New York,2006.

9. William K, John B. A Practical Guide to the Interpretation of CardioPulmonary Exercise Tests (1st Edition). Oxford University Press: Oxford,2014.

10. Binder RK, Wonisch M, Corra U, Cohen-Solal A, Vanhees L, Saner H, Schmid JH. Methodological approach to the first and second lactate threshold in incremental cardiopulmonary exercise testing. Eur J Cardiovasc Prev Rehabil 2008; 15 (6):726-34.

11. Hollmann W. The relationship between $\mathrm{pH}$, lactic acid, potassium in the arterial and venous blood, the ventilation, PoW and pulse frequency during increasing spirometric work in endurance trained and untrained persons. Sports Med 2001; 31: 315. doi.org/10.2165/00007256-200131050-00002.

12. Sun XG, Hansen JE, Garatachea N, Storer TW, Wasserman K.. Ventilatory efficiency during exercise in healthy subjects. Am J Respir Crit Care Med 2002;166 :1443-8.

13. Emerenziani GP, Gallotta MC, Meucci M, Di Luigi L, Migliaccio S, Donini LM, Strollo F, Guidetti L. Effects of Aerobic Exercise Based upon Heart Rate at Aerobic Threshold in Obese Elderly Subjects with Type 2 Diabetes. Int J Endocrinol 2015; Epub 695297. doi: 10.1155/2015/695297.

14. Hofmann P, Tschakert G.. Special Needs to Prescribe Exercise Intensity for Scientific Studies. Cardiol Res Pract 2011; 2011: 1-10.

15. Ahmaidi S, Adam B, Fabre C, Masse-Biron J, Préfaut CG. Effectiveness of individualized aerobic training at the ventilatory threshold in the elderly. J Gerontol A Biol Sci Med Sci 1997;52 (5):260-6. 
16. Prado DML, Rocco EA, Silva AG, Rocco DF, Pacheco MT, Furlan V. Effect of exercise training on ventilatory efficiency in patients with heart disease: a review. Braz J Med Biol Res 2016; 49 (7):e5180. doi:10.1590/1414431X20165180.

17. Ghosh AK. Anaerobic Threshold: Its Concept and Role in Endurance Sport. Malays J Med Sci 2004; 11 (1):24-36.

18. Varray A, Mercier J, Terral C, Prefaut C. Individualized aerobic and high intensity training for asthmatic children in an exercise readaptation program: is training always helpful for better adaptation to exercise? Chest 1991; 99: 57986.

19. Fleck SJ, Kraemer WJ. Designing Resistance Training Programs (4th Edition). Human Kinetics: Lower Mitcham,2014.

20. Howley ET, Bassett DR, Welch HG. Criteria for maximal oxygen uptake: review and commentary. Med Sci Sports Exerc 1995; 27 (9):1292-301.

21. Moreira A, Delgado L, Haahtela T, Fonseca J, Moreira P, Lopes C, Mota J, Santos P, Rytilä P, Castel-Branco MG. Physical training does not increase allergic inflammation in asthmatic children. Eur Respir J 2008; 32 (6):1570-5.

22. Gaskill SE, Walker AJ, Serfass RA, Bouchard C, Gagnon J, Rao DC, Skinner JS, Wilmore JH, Leon AS. Changes in Ventilatory Threshold with Exercise Training in a Sedentary Population: The Heritage Family Study. Int J Sports Med 2001; 22: 586-92.

23. Wasserman K. Anaerobic threshold and cardiovascular function. Monaldi Arch Chest Dis 2002; 58 (1):1-5.

24. Carroll N, Sly P. Exercise training as an adjunct to asthma management? Thorax 1999; 54: 190-1. 
25. Ingle L, Sloan R, Carroll S, Goode K, Cleland JG, Clark AL. Abnormalities of the Ventilatory Equivalent for Carbon Dioxide in Patients with Chronic Heart Failure. Pulm Med 2012; 2012: 589164. doi:10.1155/2012/589164.

26. Neder JA, Berton DC, Müller PT, Elbehairy AF, Rocha A, Palange P, O'Donnell DE. Canadian Respiratory Research Network. Ventilatory Inefficiency and Exertional Dyspnea in Early Chronic Obstructive Pulmonary Disease. Ann Am Thorac Soc 2017; 14 (1):22-9.

27. Neder JA, Nery LE, Silva AC, Cabral A, Fernandes A. Short term effects of aerobic training in the clinical management of moderate to severe asthma in children. Thorax 1999; 54: 202-6. 


\section{Table 1}

Ventilatory characteristics of measured values pre- and post- 7-week intervention $(n=$

6)

\begin{tabular}{|c|c|c|c|}
\hline Characteristics & Pre- & Post- & $p$-value \\
\hline $\begin{array}{c}\mathrm{VO}_{2 \max } \\
\left(\mathrm{ml} \cdot \mathrm{kg}^{-1} \cdot \mathrm{min}^{-1}\right)\end{array}$ & $34.08 \pm 2.21$ & $35.96 \pm 2.15$ & 0.0004 \\
\hline $\begin{array}{c}\text { Resting } \mathrm{VE} / \mathrm{VO}_{2} \\
\text { (L) }\end{array}$ & $58.17 \pm 8.66$ & $42.01 \pm 2.53$ & 0.0024 \\
\hline $\begin{array}{c}\text { Nadir } \mathrm{VE} / \mathrm{VO}_{2} \\
\text { (L) }\end{array}$ & $25.00 \pm 1.41$ & $21.50 \pm 1.52$ & 0.0004 \\
\hline $\begin{array}{c}\text { Resting } \mathrm{VE} / \mathrm{VCO}_{2} \\
\text { (L) }\end{array}$ & $43.67 \pm 3.56$ & $41.50 \pm 3.45$ & 0.0029 \\
\hline $\begin{array}{c}\text { Nadir } \mathrm{VE} / \mathrm{VCO}_{2} \\
\text { (L) }\end{array}$ & $30.50 \pm 1.64$ & $28.17 \pm 1.17$ & 0.0026 \\
\hline $\begin{array}{c}\text { AeT } \\
\left(\mathrm{ml} \cdot \mathrm{kg}^{-1} \cdot \mathrm{min}^{-1} \text { of }\right. \\
\left.\mathrm{VO}_{2}\right)\end{array}$ & $20.10 \pm 2.47$ & $24.53 \pm 2.87$ & 0.0024 \\
\hline $\begin{array}{c}\text { HR at AeT } \\
\left(\text { beats· } \min ^{-1} \text { ) }\right.\end{array}$ & $100.67 \pm 3.56$ & $107.83 \pm 2.56$ & 0.0002 \\
\hline
\end{tabular}

* Data are mean values (SD), $n=$ number of subjects 
Table 2

Differences in measured values pre- and post- 7-week intervention $(n=6)$

\begin{tabular}{|c|c|c|c|}
\hline Characteristics & Mean difference & $\begin{array}{c}95 \text { \% CI mean } \\
\text { difference }\end{array}$ & $\begin{array}{c}\text { Mean difference } \\
(\%)\end{array}$ \\
\hline $\mathrm{VO}_{2 \max }$ & $\begin{array}{c}1.90 \pm 0.57 \\
\left(\mathrm{ml} \cdot \mathrm{kg}^{-1} \cdot \mathrm{min}^{-1}\right)\end{array}$ & $\begin{array}{c}1.30 \text { to } 2.50 \\
\left(\mathrm{ml} \cdot \mathrm{kg}^{-1} \cdot \mathrm{min}^{-1}\right)\end{array}$ & $5.58 \pm 1.67$ \\
\hline Resting $\mathrm{VE} / \mathrm{VO}_{2}$ & $\begin{array}{c}-16.17 \pm 7.00 \\
\text { (L) }\end{array}$ & $\begin{array}{c}-23.51 \text { to }-8.82 \\
\text { (L) }\end{array}$ & $-28 \pm 12.03$ \\
\hline Nadir VE/ $/ \mathrm{VO}_{2}$ & $\begin{array}{c}-3.50 \pm 1.05 \\
\text { (L) }\end{array}$ & $\begin{array}{c}-4.60 \text { to }-2.40 \\
\text { (L) }\end{array}$ & $-14 \pm 4.2$ \\
\hline Resting $\mathrm{VE} / \mathrm{VCO}_{2}$ & $\begin{array}{c}-2.17 \pm 0.98 \\
(\mathrm{~L})\end{array}$ & $\begin{array}{c}-3.20 \text { to }-1.13 \\
\text { (L) }\end{array}$ & $-4.97 \pm 2.24$ \\
\hline Nadir VE/VCO 2 & $\begin{array}{c}-2.33 \pm 1.03 \\
(\mathrm{~L})\end{array}$ & $\begin{array}{c}-3.42 \text { to }-1.25 \\
\text { (L) }\end{array}$ & $-7.64 \pm 3.38$ \\
\hline AeT & $\begin{array}{c}4.46 \pm 1.93 \\
\left(\mathrm{ml} \cdot \mathrm{kg}^{-1} \cdot \mathrm{min}^{-1}\right)\end{array}$ & $\begin{array}{c}2.44 \text { to } 6.49 \\
\left(\mathrm{ml} \cdot \mathrm{kg}^{-1} \cdot \mathrm{min}^{-1}\right)\end{array}$ & $22.19 \pm 9.62$ \\
\hline HR at AeT & $\begin{array}{l}7.17 \pm 1.72 \\
\left(\text { beats } \cdot \mathrm{min}^{-1} \text { ) }\right.\end{array}$ & $\begin{array}{l}5.36 \text { to } 8.97 \\
\text { (beats } \cdot \mathrm{min}^{-1} \text { ) }\end{array}$ & $7.12 \pm 1.71$ \\
\hline
\end{tabular}

* Data are mean values (SD), $n=$ number of subjects 
Fig. 1 General fitness level characteristics of pre- and post- 7-week intervention $(n=$ 6)

a) AeT location; b) HR at AeT; c) $\mathrm{VO}_{2 \max }$

${ }^{*} n=$ number of subjects

Fig. 2 Characteristics of measured pre- and post- 7-week intervention ventilatory equivalents values $(n=6)$

a) resting $\mathrm{VE} / \mathrm{VO}_{2}$; b) nadir $\mathrm{VE} / \mathrm{VO}_{2}$; c) resting $\mathrm{VE} / \mathrm{VCO}_{2}$; d) nadir $\mathrm{VE} / \mathrm{VCO}_{2}$

$* n=$ number of subjects 